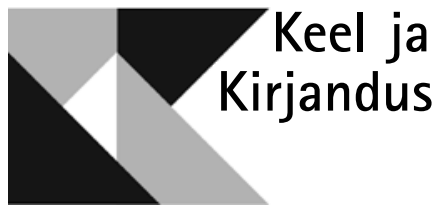

\title{
RELIGIOOSSED PAASTUD JA PIDUSTUSED SETO KULTUURI REPRESENTATSIOONIDES
}

\author{
ANDREAS KALKUN
}

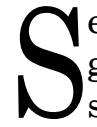

eto kultuuri kirjeldustes, mis on pärit XIX sajandi lõpust ja XX sajandi algusest, mainitakse tähelepanuväärselt tihti nii setode kurnavaid paastusid kui ka kohutavaid joominguid. Ortodokssete setode kolm nädalasisest paastupäeva ja neli pikemat aastapaastu tundusid luterlastele irratsionaalsed ja tervistkahjustavad ning eestlaste loodud setode antropoloogilistes ja tervishoiulistes kirjeldustes rõhutatakse rahva „üldise räpasuse” kõrval ikka paastuaegsest kehvast toitumusest tulenevaid tervisehädasid. Juba varaseimates seto kultuuri kirjeldustes kritiseeritakse paastumise kõrval ka õigeusu kirikukalendrist tulenevate pühade rohkust ning liigset alkoholi tarvitamist ja eriti eetri joomist. XX sajandi alguses saab setode populaarsetes representatsioonides retooriliseks topos'eks metsik ja irratsionaalne pidu, nn guljänje, kus süüakse, juuakse ja lõbutsetakse kuni verise tülini.

Setode asuala jääb tänapäeval Eesti Vabariigi ja Venemaa Föderatsiooni piirile. Setode territoorium on alates Vene riikluse kujunemisest kuulunud Vene võimkonda või mõjusfääri ja õigeusu kiriku valdusse. Ka pärast Põhjasõda, mil Liivimaa liideti Vene valdustega, jäid setod endiselt Pihkva kubermangu. Eestlaste rahvuslik ärkamine ei ületanud kubermangupiire ning on väidetud, et vana, keskajale omane elulaad püsis Setomaal kuni 1920. aastatel alanud intensiivse eestistamiseni (Valk 2005: 128-129; Kuutma 2005: 133). Veel XX sajandi esimesel poolelgi on erinev usutunnistus hoidnud ranget piiri keeleliselt sarnaste luterlastest lõunaeestlaste ja õigeusklike setode vahel. 
Samamoodi on olnud jäik piir setode ja venelaste vahel. Vaatamata sellele, et setod kuulusid venelastega samadesse kogudustesse, nimetasid venelased neid pooleusulisteks ning keelebarjääri tõttu tuli ka segaabielusid harva ette (Paas 1928; Hurt 1904a: 190-191).

Alates XIX sajandi lõpust on setod olnud Eesti ja Soome keele- ja kultuuriuurijate fookuses ning seto folkloori ja kombeid on usinalt jäädvustatud. Tänu rikkale laulutraditsioonile ja eripärastele kommetele on setode juurest ikka otsitud ürgset soomeugrilikku ning seda, mis mujalt on kaduma läinud. Oma mahajäämuse ja harimatuse tõttu olid setod rahvakultuuri uurijatele „ideaalseteks ürgeestlasteks", ${ }^{1}$ keda uurides loodeti valgust heita kogu eesti ja soome-ugri minevikule. Õilsa metslase kuvandiga (vt Plath 2001) paralleelselt käibisid aga ka võõristavad mahajäämust, rumalust ja viletsust rõhutavad representatsioonid. Pärimuse jäädvustamine oli nagu ikka selektiivne, koguti vaid ideoloogiliselt sobivat, ning seetõttu on näiteks setopärastele õigeusu tõlgendustele ja usupraktikatele suhteliselt vähe tähelepanu pööratud. Seda osa pärimusest on peetud liiga „slaavipäraseks” ja „uueks” ning uurijad on eelistanud seto kultuuri kogu kirevusest välja sõeluda just „vana” ja „eelkristlikku”.

Kui 1918. aastal sai setode territoorium Eesti Vabariigi osaks, muutus ametlikuks poliitikaks setode integreerimine ning piirkonna haridusliku ja majandusliku mahajäämuse likvideerimine (vt Lõuna 2003; Jääts 1998). Pärast 1921 . aastal toimunud perekonnanimede andmist, eestikeelse koolivõrgu sisseseadmist, seto ja vene koguduste lahutamist ja mitmesugust muud intensiivset lõimimistegevust hakkas Setomaa radikaalselt moderniseeruma ja eesti kultuuri mõjusfääri nihkuma (vt Kuutma 2005: 133). Kui veel XX sajandi alguses oli setode autonoomsus olnud iseenesestmõistetav ning valgustatud rahvateadlased pidid vaeva nägema selgitamaks „tavalisele eestlasele”, et setod on üldse nende sugulased (Hurt 1989: 147), siis nüüd muutusid setod aegamisi kaksikidentiteediga eestlasteks (Jääts 1998: 126). XX sajandi lõpus jõudsid setod eestlaseks assimileerumise hirmus nii kaugele, et neid esindav Seto Kongress kuulutas nad eestlastest eraldi rahvaks. ${ }^{2}$

\section{Setod kui Teised: representatsiooniküsimused}

Setomaa ja setode piiripealsus on teinud neist eesti kultuuri jaoks ideaalse Teise. Seoses sellega, et kirjakultuur jõudis setodeni suures osas alles XX sajandi alguskümnendeil, on neist kirjutajad olnud n-ö kõhurääkija positsioonil ${ }^{3}$ (vt Ritchie 1993), vahendades vaikivate ja enese representatsiooni suhtes kontrolli mitteomavate setode häält ja paigutades neid representeerijale sobivasse rolli. Eestlaste loodud etnograafilised kirjeldused ja muud representatsioonid kandsid kolonialistlikku ideoloogiat ja rõhutasid sageli setode primitiivsust ja algupärasust ning rahvaluulekogujad kirjutasid ka otsesõnu, et setod on oma

\footnotetext{
${ }^{1}$ Indrek Jäätsu tarvitatud kujund (1998: 37).

${ }^{2}$ Esimese Seto Kongressi organiseerisid eestlased ja see toimus 9.-10. oktoobril 1921. aastal. Tol ajal oli eesmärgiks pigem setosid eestistada (Jääts 1998: 51). Omaaegse setode esinduskogu tööd jätkanud Seto Kongress võttis 2002. aastal vastu deklaratsiooni, mis kuulutas setod eraldi rahvaks (Sarv, Õ., Sarv, A. 2003).

${ }^{3}$ Susan Ritchie metafoor kritiseerib Teist representeerivat folkloristikat, mis võtab endale õiguse kõnelda „tumma” rahva eest, et päästa tema pärimust unustusse vajumisest või hävimisest.
} 
arengus sada (Põldmäe 1938: 3) või kakssada aastat (Hurt 1989: 42) eestlastest maas. Setode representatsioonid sisaldasid endas sageli teatud allegoorilist või moraliseerivat elementi, setode kujutamine teenis eesti ajaloouurimist või andis õpetliku tulevikuvaate. Setode mahajäämuse ja konservatiivsuse retoorika seostus kirjutistes sageli just õigeusuga ja vene mõjudega. Setode religioosseid praktikaid kirjeldati grotesksena ning rõhutati „rahvakese” irratsionaalsust ja metsikut temperamenti.

Kui pastor Jakob Hurt tegi Vene Geograafiaseltsi stipendiaadina Setomaal välitöid, lõi ta väga mõjuka kultuurikirjelduse (Hurt 1904a) ${ }^{4}$, milles öeldut ja ütlemise viisigi hakati edaspidises setodest kirjutamise diskursuses kordama ${ }^{5}$. Vastavalt geograafiaseltsi nõuannetele ${ }^{6}$ kirjeldas Hurt esmalt paikkonna administratiivset jaotust, kohalikku loodust ja kliimat ning seejärel piirkonnas elavaid inimesi ja nende kombeid. Inimeste puhul kirjeldati nende välimust ja iseloomu, aga anti näiteks ka ülevaade tüüpilistest haigustest. Hurt väidab, et setode asualal on soodne ja tervist turgutav kliima, nii et isegi keegi Peterburist Petserisse kolinud „surmakandidaat” on sealses kliimas tervenenud. Setode tüüpilisimad haigused pole Hurda järgi seotud kliimaga, vaid nende „kultuuriliselt mahajäänud eluviisiga” ning tulenevad eelkõige „mustusest ja paastuaegsest kehvast toitumisest” (Hurt 1904a: 187-188). Samas kirjutab Hurt ka, kuidas alkoholism on nagu katk jõudnud „meie väikeste setukeste” kodudesse, ning kirjeldab pulmapidu, kus eetriplahvatuse tagajärjel leidsid kuus pulmalist oma otsa ning paljud said raskeid põletushaavu (Hurt 1904a: 205). ${ }^{7} \mathrm{Ka}$ setosid tutvustav Villem Buck leiab nagu paljud hilisemadki kirjutajad, et lisaks setode kurnavatele paastudele on just „liikva” joomine nende tervisele laastavalt mõjunud (Buck 1909: 12).

\section{Setode usuelu: formaalsed kombed või sügav usk?}

Vaatamata sellele, et kristlik misjon ja ristiusustamine jõudsid setode asualale juba sajandite eest, ${ }^{8}$ on setode XIX sajandi lõpus ja XX sajandi alguses loodud representatsioonides tavaks rõhutada nende usulist ignorantsust ja õigeusu religioosseid praktikaid kui formaalseid kombetäitmisi, mis pole suutnud eelkristlikku usundit hävitada. Hurt ütleb oma krestomaatilises kirjutises, et setode õigeusk on „välist laadi”, see on kogum tseremooniaid ja tavasid, mille tähenduse üle ei küsita. Hurda järgi täidavad setod küll virgalt kirik-

\footnotetext{
${ }^{4}$ Aruanne ilmus esmalt 1903. aastal venekeelsena, aasta hiljem avaldati see Hurda enda saksakeelses tõlkes.

${ }^{5}$ Olen teisal Foucault'st inspireerituna nimetanud Hurta diskursuse rajajaks (Kalkun 2011: 92, vt ka Foucault 2000), rõhutamaks Hurda rolli setode representatsiooni kujunemisel. Autoriteetse Hurda kirjutised andsid hilisematele kirjutajatele kätte setodest rääkimiseks sobivad teemad, tooni ja keele.

${ }^{6}$ Reisiaruande koostamisel lähtus Hurt nähtavasti Vene Geograafiaseltsi etnograafiaosakonna esimehe V. Lamanski „Etnograafiliste andmete kogumise programmis” antud nõuannetest. Hiljem tunnustas Vene Geograafiaselts Hurda tööd setode uurimisel oma kõrgeima autasu, Konstantini medaliga (Ribenis 1993: 671-672).

${ }^{7}$ Traagilise sündmuse representatsioonidest põhjalikumalt vt Aabrams, Kalkun 2013: 208-209.

${ }^{8}$ Irboska Püha Nikolai kiriku kohta on kirjalikke teateid 1340. aastast, kuid arvatakse, et kirik on olnud seal juba XII või isegi XI sajandil. 1473. aastal asutati Petseri klooster (Piho 2011).
} 
likke kombeid (nt paastuvad ja osalevad ristikäikudel), kuid jumalateenistus on setode jaoks nagu näitemäng, mille tähendus, nagu ka pühakirja tõeline sisu, on seitsme pitseriga suletud. Luteri pastor ahastab, et setode hulgas on kümne käsu ja meieisapalve tundmine ülimalt harv, nagu ka tõeline südameusk (Hurt 1904a: 192-193). ${ }^{9}$ Sellest, kuidas setod kirikus püstijala magavad ja kirikuslaavikeelsetest teenistustest aru ei saa, oli kirjutanud oma etnograafilises kirjelduses juba Oskar Kallas (1898: 179).

XX sajandil korduvad seto usuelust kirjutajate tekstides samad motiivid, rõhutatakse seda, kuidas keelebarjääri tõttu on setode usk jäänud pinnapealseks ning sellise halvasti omandatud kristluse varjus elab rikkalik eelkristlik pärand. ${ }^{10}$ Tõepoolest, veel XX sajandi alguses oli setode vene keele oskus väga harv nähtus, nagu ka lugemisoskus, mis tähendas, et protestantlikul moel kodusest jumalasõnauurimisest ei saanud juttugi olla. Samal ajal pole olukord siiski nii ühemõtteline, on selge, et samas külas elavad preestrid ja setod pidid kuidagi suhtlema ning ilmselt leidus neidki, kes vastastikku seto või vene keele omandasid. 1776. aastast pärinev Värska preestri Ankita Jakovlevi seto keelde tõlgitud pihtimiskorra kavagi (Laur 1928) näitab, et kirikus suhtlemine ja usuõpetus võis üksikutel juhtudel olla täiesti emakeelne. 1885. aastal väideti küll olevat Setomaal vaid üks preester, kes suutis seto keeles suhelda (Setumaa 1928: 89), ning 1919. aastal, enne vene ja eesti koguduste eraldamist, oli eestikeelne preester kahes koguduses (Lõuna 2003: 43).

Samas leidus juba XIX sajandi lõpus vähesel määral venekeelses koolis käinud setosid, kellest mõned said ka religioosse hariduse. 1885. aasta loenduse järgi oli setode hulgas 80 kirjaoskajat (Setumaa 1928: 92). Jõukamad setod panid oma poegi kooli, et need vene keele oskuse abil saaksid võimaluse sotsiaalselt tõusta (vt Jääts 1998: 32). XIX sajandi lõpus asutati mitmeid venekeelseid kirikukoole ning sel ajal suurenes ka Petserimaal koolis käivate laste arv 150-ni (Setumaa 1928: 92). Venekeelne haridus võis tähendada assimileerumist, kuid leidus ka näiteid setodest, kes vaatamata karjäärile venekeelses keskkonnas ei unustanud oma seto identiteeti. Näiteks seto päritolu Velikije Luki (hiljem ka Petseri) kloostriülem isa Arkadi kogus seto rahvalaule ja saatis Hurdale (vt Hurt 1904b: XI; Aabrams, Kalkun 2013: 200).

1940. aastal Setomaal rahvaluulet kogunud Ello Kirss kirjutab oma välitöödel kohatud 1867. aastal Luhamaal sündinud Semjon Luigest ja tema usuelust. ${ }^{11}$ Pilt on väga erinev tavalisest seto representatsioonist: Semjon olevat lugenud venekeelset vagakirjandust, suhelnud regulaarselt Petseri kloostrielanikega ja püüdnud jäljendada pühakute kasinaid eluviise. Ilmselt leidus selliseid ebatüüpilisi haridust saanud, lugevaid ning aktiivselt ja teadlikult religioossete institutsioonidega suhtlevaid setosid teisigi.

\footnotetext{
${ }^{9}$ Vene talurahvakultuuri uurijad on märganud, kuidas mitteõigeuskliku või eriti protestantliku taustaga uurijad on liiga kergekäeliselt kaldunud rahvalikku õigeusku pidama formaalseks kombetäitmiseks. Protestantlik arusaam religioonist eeldab individuaalset usku, pühakirja tundmist ja arusaamist usuõpetuse põhialustest ning seetõttu on kirjaoskamatu ja rahvapärane vagadus võinud paista usukülmuse või pooleusulisusena (dual faith kui paganluse ja kristluse segu, selle kohta vt Lewin 1990: 166 jj). Kuigi vene talupojad ei pruukinud tunda formaalset usuõpetust, olid nad pühendunud rituaalidest osavõtjad. Kuigi talupoegade religioossed praktikad ei olnud ehk kooskõlas ametlike dogmade ja reeglitega, ei tähendanud see ilmtingimata seda, nagu poleks religiooni võetud tõsiselt (vt Heretz 2008: 8-9).

${ }^{10}$ Nt Hagu 1999; Rammul 1935: 49; Usstav 1908: 7-8.

${ }^{11}$ ERA II 286, 62/4 < Vastseliina v, Saagri k < Se, Leimanni k - Ello Kirss < Semjon Luik (1940).
} 


\section{Setode paastumine: meditsiiniline või religioosne tõlgendus?}

Vaatamata sellele, et võõrad kultuurikirjeldajad ei pidanud setosid väga religioosseteks, identifitseerisid setod XIX sajandi lõpus ennast oma usu kaudu ${ }^{12}$ ning õigeusklikud paastud ja kirikupühad olid setoks olemise tähtsad komponendid. Õigeusklikule vagadusele iseloomulik paastumine, armulauamüstika, aga ka toiduohvrid, toidu almustena jagamine ja mälestussöömingute tähtsustamine olid olulisel kohal ka setode rahvalikes õigeusu tõlgendustes. Söögi valmistamine ja selle jagamine ning söögist loobumine oli eriliselt tähenduslik seto naiste jaoks. Usk sellesse, et vaestele antud almused võiksid mõjutada kalliste kadunukeste või toidujagaja isiklikku heaolu, vormis seto naiste söögiga seotud tavandit ja kombestikku (vt Kalkun 2008).

Nii toidu valmistamine, söömine kui ka söögist keeldumine on seto kultuuris funktsioneerinud jõuliste kultuuriliste metafooridena. Toidukeelud on toiminud ilmselt setodelgi kristliku identiteedi tugevdajatena (vt ka Grumett, Muers 2010: 35) ning tõmmanud selge piiri paastuvate omade ja paastu rikkuvate võõraste vahele. Eesti Rahvaluule Arhiivis säilitatavatest tekstidest, milles setod mõtisklevad oma paastumiskombe üle, tuleb välja, et paast on olnud veel XX sajandi alguses setoks olemise oluline osa. Rõhutatakse traditsiooni: paastumine on ajast aega olnud ja seto rahva esivanemad on sellest kinni pidanud. Sellistes juttudes vastandutakse kas eksplitsiitselt või implitsiitselt protestantlikele eestlastele (või nagu setod ütlevad mõtsigu' (metsikud), st mitteõigeusklikud), kes ei paastu. Traditsioonilise jutu järgi on paastust kõrvale hoidvaid eestlasi hävingust päästnud vaid Jeesus Kristuse lõpmatu halastus.

Jummal' tahtsõ vanast, et eeśtläisi olõsi-s olõmahki, et nimä' ei paasta' paastu. A Eesus Krbstus üt'les, et näid om kah väega pal’lo, et jätämi nimä’ kah elämä viil. ${ }^{13}$

ERA II 286, 160 (132) < Se, Palo k - Ello Kirss < Ode Palo, s 1869 (1940).

Ortodokssete setode jaoks on söömine või söögist loobumine olnud eetilismoraalne valik. Paastumine kui ihaldatav, kuid füüsilist ja vaimset pingutust nõudev seisund on paljude religioossete setode jaoks olnud iganädalane praktika.

Eestlaste loodud seto kultuuri kirjeldustes mainitakse paaste kui kurioosumit või tervistkahjustavat ja arusaamatut tava. Protestantlik pastor Hurt käsitles paastumist kui meditsiinilist, mitte religioosset nähtust, ning sama teed lähevad nii eestlasest õigeusu preester Karl Usstav oma kultuurikirjelduses „Pihkwa eestlased” (1908: 7-8) kui ka vasakpoolne literaat Villem Buck oma teoses „Petseri eestlased” (1909: 12). Mõlemad nendivad selgelt Hurdale toetudes, et paastuaegne kehv toitumine on mõjunud laastavalt setode tervisele. Ka XX sajandi alguse eesti teaduskirjandus kordab sama. „Petserimaa tervishoiuline kirjeldus" nendib neutraalselt, et paastude tõttu on „lihatoitude tarvitamine võrreldes teiste maakondade elanikkudega võrdlemisi vähene"

${ }^{12}$ Usk on tõmmanud range piiri setode ja luterlastest eestlaste vahele. Veel XIX sajandil võisid setod end „maarahva” kõrval religioosse kuuluvuse järgi ka venelaseks nimetada (Kreutzwald 1953 [1848]: 108; Sarv 2000: 62; Reier 1922: 174).

${ }^{13}$ Tekstide keeleline kuju on siin ja edaspidi nii, nagu rahvaluulekogujad on seda märkinud. Tõlge: 'Jumal tahtis vanasti, et eestlasi poleks olemaski, kuna nad paaste ei pea. Aga Jeesus Kristus ütles, et neid on ka väga palju, jätame nad ka elama veel.' 
(Rammul 1935: 50), kuid maakonna tervishoiuliste olude kirjelduses kõneldakse rannaäärsete venelaste puhul suisa sagedasest alatoitlusest:

Nendel on toiduaineteks peaasjalikult kartul, kala ja kurk. Pikad paastud keelavad sedagi korralikult tarvitamast, mille tõttu tekib tihti alatoitlus. Alkoholi ja eetrit (liikvat) tarvitatakse rohkesti (Setumaa 1928: 107).

Õigeusklike setode iganädalased paastupäevad olid esmaspäev, kolmapäev ja reede, vastavalt Jeesuse sünni, tema äraandmise ja surma mälestuseks. ${ }^{14}$ Lisaks sellele ei söödud enne pühapäevast kirikusse minekut. Neli suuremat paastuaega aastas olid lihavõttepaast (seitse nädalat), jõulupaast (kuus nädalat), maarjapaast (kaks nädalat) ja peetripaast (kuni kaks nädalat, sõltub lihavõtte kuupäevast, kuna algab nädal pärast kolmainupüha) ${ }^{15}$ Lisaks nendele tunti ühepäevaseid täielikke söögikeelde kirikupühade eelõhtutel: paastuti näiteks epifaania (viiristmine), jõulu (talsipühi) ja lihavõtte (lihavõõdõ ) laupäevadel. ${ }^{16}$ Mõnes peres oli tavaks paastuda veel nt jaanilaupäeval, issandamuutmise pühal (paasapäiv), ristiülendamise pühal (vissenja) või Ristija Johannese pea maharaiumise päeval (ivanaskorona). Lisaks oli külades tuntud lokaalsemaid paastupäevi, näiteks oli piirkondi, kus paastuti Pihkvamaa pühaku Nikanderi auks (üks nädal) ${ }^{17}$ ning Peaingel Miikaeli auks (kaks nädalat). ${ }^{18}$

Kes nädalasiseseid paastupäevi ja nelja pikemat aastapaastu ei suutnud pidada, muutsid oma toitumisharjumusi vähemalt suureks paastuks. Kes kogu paastu ei jõudnud pidada, loobus söögist esimesel, keskmisel ja viimasel nädalal. ${ }^{19}$ Paastumine tähendas peale söögikeeldude ka mitmeid muid piiranguid. Setod uskusid, et igasugused ilmalikud lõbustused, nagu laulmine ja tantsimine, on paastu ajal patt, aga samuti näiteks seksuaalelu, muinasjuttude rääkimine ${ }^{20}$, suhkruga tee joomine, seebiga pea pesemine $e^{21}$ jne. Paastuaegsed käitumisnormid olevat keelanud lihast ja piimast söögilauas rääkidagi. ${ }^{22}$

${ }^{14}$ Sagedamini peeti kinni vaid kolmapäevasest ja reedesest paastust. Aga nagu tsaaririigi muudes piirkondades, oli setode hulgas tuntud ka esmaspäevane paast, mis on olnud selgelt rahvalikku algupära vagade kloostrielanike sukhoiadenie imiteerimine. Ametliku kirikukalendri rikastamine veel ühe paastupäevaga ning seega nädala profaansest ajast veel ühe päeva pühaks eraldamine kuulus rahvaliku vagaduse juurde (vt Heretz 1997: 71).

${ }^{15}$ Kaht viimast nimetati ka „kergeks paastuks”, kuna neid nii rangelt ei peetud (nt H II $63,481 / 2<$ Se - Jaan Sandra (1900)).

${ }^{16}$ ERA II 209, 156/7 (9) < Se, Vilo v, Ungavitsa k - Ello Kirss < Maarja Kink, s 1871 (1939).

${ }^{17}$ ERA II 209, 122/5 (1) < Se, Vilo v, Lõkova k < Serga k - Ello Kirss < Vassil Liivapuu, s 1869 (1939).

${ }^{18}$ Meremäe kandis ja Usinitsas olevat peetud mihklipaastu, kuna usuti, et see aitab marutõve vastu (ERA II 286, 126/8 (93) < Se, Vastseliina v, Ljuta k - Ello Kirss < Ode Tammist, s 1868 (1940); ERA II 155, 394/5 (187) < Se, Mäe v, Soelaanõ k - Nikolai Sõrmus < Aleksei Ossik, 78 a (1937)).

${ }^{19}$ ERA II 209, 122/5 (1) < Se, Vilo v, Lõkova k < Serga k - Ello Kirss < Vassil Liivapuu, s 1869 (1939).

${ }^{20}$ ERA II 194, 354 (2) < Se, Meremäe v, Serga k - Ello Kirss < Maarja Vahtramägi, s 1887 (1938).

${ }^{21}$ ERA II 286, 126/8 (93) < Se Vastseliina v, Ljuta k - Ello Kirss < Ode Tammist, s 1868 (1940).

${ }^{22}$ ERA II 296, 449/50 (12) < Se, Vilo v, Ojavere k - Maria Linna (1941). 
Paastutabusid võeti tõsiselt ning Eesti Rahvaluule Arhiivi on talletatud hulgaliselt hoiatavaid jutte, milles väljendatakse kartust paastu rikkumise ja sellele järgnevate karistuste pärast. ${ }^{23}$ Järgnevas loos räägib Jevdokia Palo paastu rikkumisest (laulmine, õlle joomine), mis toob kohe kaasa ränga karistuse.

Mul velel lät's poig kroonu pääle minemä. Ol'l kangõ paastu aig, vana paastu keśkmäne nätäl', riśti nätal', kannahtamise riśti nätäl'. Tei' nimä' ollõ' kbilk' ja val 'miśti pito. Ku hallõkõnõ mul ol'l! Mina mõt'li, et ku nimä' nakkasõ pito pidämä, tiiä-i, kohe ma lääsi’ ku nakkasõ laulma. Ma paastu aigu ei taha' pidostõ hel'lü. Velenaańe lät's hobõst sü̈̈t'mä, hopõn lei jalga pite, nii et tuust ol'l viil jummal' hoitmah, et luu kat'ski es lä̈̈'. Es tulõ inämb kinkõlgi pito, es olố kinkõlgi inämb hüvvämiilt. Teno viil jumalalõ, et jumal' süt'üt' jala aŕa kah. ${ }^{24}$

ERA II 286, 159/60 (131a) < Se, Palo k - Ello Kirss < Ode Palo, s 1869 (1940).

Seto paastujatele olid eeskujuks levinud legendid pühakutest ja metsaüksinduses paastujatest (Loorits 1959: 32), kes elasid aastaid, süües vaid taimi või armulaualeiba (prosforaad). ${ }^{25}$ Seto pärimuses leiduvad Jumalaema elu puudutavad legendid sisaldavad paastumise ja prosforaadest toitumise episoode (vt Kärner 2003: 57), aga selliseid lugusid on räägitud ka mitmete seto kohalike pühameeste kohta. Nii Mõla kirikuga seotud püha Onufri kui õndsa Matvei kohta käiv pärimus, aga ka püha Nikanderi pühakulood on seotud just selliste motiividega. Samas on paastuseletusi, mis väidavad, et tegemist on nn imitatio Christi'ga, Kristuse elu ja kannatuste jäljendamisega (vrd Bynum 1992: 255-259). Seto legendi järgi polevat Kristus-laps kolmapäeviti ja reedeti rindagi söönud ${ }^{26}$ ning lihavõttepaastuga kujutati Kristuse kõrbes olekut ja tema ristisurma.

Kolmapääväne ja riidene paastupäiv sai tuust, et Kristus-Jummal kolmapäävä ja riidi nissa es sü̈̈̈. „Suur paast” sai tuust, et Kristus-Jummal inne hukkamist kuus nädälit laanõh paast, ja säitsmes nätäl om timä hukkamise nätäl. Muu' paastu', nigu Piitre ja Maarja paastu', ja talsipühi paastu' omma' meile mälehtüsest pühhist mehist kingitü. Kuis mi muido noidõ päivi vasta hinnäst õigõ valmista? Õga meil jo raamatid ei olõ. Muido kirja ka mi ei tunnõ. Nägä olõs sis küll illos, ku mi käest pühäsi’ ja paast á́ võõdõtasi! Sis olõssi mi ku pümme’ pagana’. Paast om jo Jumalast, niigu

${ }^{23}$ Olen uurinud paastuaegse laulmiskeelu järgimist Setomaal Värska kirikukooris ja külakooris Leiko ning leidnud, et osa paastutabudest elavad siiamaani (Kalkun 2004; Kalkun, Ojamaa 2009).

${ }_{24}$ 'Mu vennal hakkas poeg sõjaväkke minema. Oli kõva paastuaeg, Suure Paastu keskmine nädal, kannatamise ristinädal. Nad tegid õlut ja valmistusid peoks. Mul oli nii kahju! Ma mõtlesin, et kui nad hakkavad pidu pidama ja laulma, siis ma ei tea, kuhu põgeneksin. Ma paastu ajal ei taha peo häält kuulda. Vennanaine läks hobust söötma, hobune lõi jalaga, Jumal hoidis, et luu katki ei läinud. Polnud enam kellelgi pidu, kellelgi polnud rõõmsat tuju enam. Jumalale tänu, et Jumal parandas jala terveks.'

${ }^{25}$ Setod on uskunud armulaualeiva imelisse ja maagiliselt tervendavasse väesse. Prosforaadega viidi kodus läbi mitmeid tervendamisriitusi, sellega võis ravida näiteks ärakaetatud lapsi või loomi. Samuti usuti selle imelisse toitvusse (Loorits 1959: 18).

${ }^{26}$ Sama usuti ka mõnes Setomaa piirkonnas austatud Pühast Paraskevast (ERA II 209, 247/8 (18) < Setu, Meremäe v, Jankino k < Vilo v, Lõkova k - Ello Kirss < Ode Vislapuu, s $1846(1939))$. 
pühäsigi Jumalast ja Jumala mehist omma’. Pühä Ilja, pühä Mikul ja kõik muu' pühä' mehe' omma' paastnu', mis sis meist üldä'. Mi jo paastma õks piämegi. ${ }^{27}$

H II 63, 452/6 (5) < Se, Vastseliina - Jaan Sandra (1900).

Eesti Rahvaluule Arhiivis leiduvatest paastuseletustest on näha, kuidas õigeusklikud setod on olnud interaktsioonis luterlike küsitlejate või kujutletavate tekstide adressaatidega. Neis tekstides võib märgata, kuidas paastumisest räägitakse sageli end õigustades, justkui kartes, et vestluspartner võiks kõneleja paastumist halvustada või selle ära keelata. Nii eelmises kui järgnevas näitetekstis rõhutavad setod oma "harimatust” ning seda, et paastumine on üks neile kättesaadav viis jumalat teenida ja vaga elu elada. Kummaski tekstis diskuteerib usklik seto delikaatselt teiseusulise ja mittepaastujaga. Paljudes setode käest üles kirjutatud paastumisest kõnelevates juttudes vastandatakse paastu rikkuvaid preestreid ja ausalt paastuvaid setosid, justkui rõhutades setode „lihtsa” usu tugevust (vt ka Loorits 1959: 11).

Vanarahvas ütles, ôt suurt lihavõõdõ paastu piat paastma, sis õi või’ süvvä’ piimä ja lihha, et piat kannahtama, kuis Kristos mi iist kannaht ja mi iist lask' hinnäst vaivata. Tuuperäst mi pia paastma ja kannahtama ja piinama umma ihho Kristusõ vaiva peräst. A muidu mi mõista-i kuiki jumalat pallõlda, ku ainult paastmisõ kannahtamisõga. Mi seto rahva vanõmatõ vanõmba' ütlese', ôt paastu ommõ vaia. Mi õi saa’ ja õi või noidõ pääle kaia', kiä õi paastu' ja õi taha' sukugi paastu pitä'. Jummal õi lä̈ä kellegi päähä lüümä, õt sa süüde ja õt sa varastat ja tõõsõ aŕ tapadõ ja aŕ riisudõ vai aŕ palotat. Timä lask kõikõ inemistel tetä’ aŕ. Tuuh ilmah tulõ aru anda. ${ }^{28}$

S 88625/8 (33e) < Se, Vilo v, Petseri-Olohova k - Grigori Karulaan < Anton Täht (1934).

XX sajandi alguses hakkas Setomaa aegamisi ilmalikustuma, kuid patriarhaalses ja konservatiivses seto külas koduseinte vahele suletud naised olid need, kes paastumist nagu ka muid kaduvaid kombeid edasi kandsid. Paastumine sai seto kultuuris selgelt naiseliku märgi ning naised pidasid oma abi-

${ }_{27}$ 'Kolmapäevane ja reedene paastupäev said sellepärast, et Kristus-Jumal kolmapäeval ja reedel rinda ei söönud. „Suur paast” sai sellepärast, et Kristus-Jumal enne hukkamist kuus nädalat laanes paastus, ja seitsmes nädal on tema hukkamise nädal. Muud paastud, nagu Peetri ja Maarja paastud, ja jõulupaast on meile mälestuseks pühadest meestest kingitud. Kuidas me muidu nendeks päevadeks end ikka valmistame? Ega meil ju raamatuid ei ole. Muidu kirja ka me ei tunne. Ennäe, oleks siis küll ilus, kui meie käest pühakud/ikoonid ja paast ära võetaks! Siis oleks me kui pimedad paganad. Paast on ju Jumalast, nii nagu pühakud/ikoonid Jumalast ja Jumala meestest on. Püha Ilja, püha Nikolai ja kõik muud pühad mehed on paastunud, mis siis meist veel rääkida. Meie ju paastuma ikka peamegi.'

${ }^{28}$ 'Vanarahvas ütleb, et suurt lihavõttepaastu peab pidama, siis ei või süüa piima ja liha, peab kannatama, nii nagu Kristus meie eest kannatas ja laskis ennast vaevata. Sellepärast peame me paastuma ja kannatama ja piinama oma ihu Kristuse vaeva pärast. Muudmoodi me ei oskagi Jumalat paluda kui ainult paastumise kannatamisega. Meie seto rahva vanemate vanemad ütlevad, et paastuda on vaja. Me ei saa ja ei tohi nende peale vaadata, kes ei paastu ja ei taha sugugi paastu pidada. Jumal ei lähe kellelegi vastu pead lööma, et sa sööd ja varastad ja tapad ja riisud või põletad. Tema laseb inimestel kõik ära teha. Aga teises ilmas tuleb aru anda.' 
kaasadest palju ustavamalt kinni mõningatest religioossetest praktikatest, muuhulgas rangetest paastudest.

Naisterahva esiloomus pidä ka paastumisest pall'o kimmäbähe kińni kui mehel. Paastmine oleśs ammu seturahva seast kaonu, kui naase' tedä nii lõdvalt ja nõrgalt kińni oleśs pidänü kui mehe’. Mehe’, kes „maa puul” linnu käävä’ rabamah, närtsä korjamah jne., söövä’ kõik' ka „suurõh paastuh” läbi, mis õnnõ ette andass, kuna naase lastõga kotoh selle üle väega valvava, et paastupääväl midägi „söödävä päävä” toitu suuhhe ei saa. ${ }^{29}$

H II 63, 452/6 (5) < Se, Vastseliina - Jaan Sandra (1900).

See, et naised paastusid ja mehed ei paastunud, ei tähenda seda, et seto naised oleks oma paastuperioodil lakanud sööke valmistamast. Naised hoidsid endale eraldi anumad ja söögiriistad, et mitte „püretada” neid loomsete toi$\mathrm{du}$ ainetega $\mathrm{a}^{30}$, ja tegutsesid edasi toiduvalmistajate ja -pakkujatena ${ }^{31}$. Naised hoolitsesid ka selle eest, et lapsed paastuksid, ning arhiivi on talletatud hulgaliselt lastehirmutusi, mis pidid ära hoidma laste soovi paastust üle astuda. On teada juhuseid, kus religioosne paastumine on usklikke setosid mõjutanud toitumisharjumusi radikaalselt ja lõplikult muutma. ${ }^{32}$

Paastu asi jal nisama. No jovva-i suurõ inemise’ ar pitä', a vanast ol'l lat'silgi sääne kõrd, et kat's aastakka imet' imä, kolmada aastaga ańni sü̈̈dävät ja nel'ädä aastaga pańni paastma. Üt's pap'inaańe kül' kbnõli, et säädüs om latsil säit'sme aastani’ süvvä'. [---] Mul hindälgi om paastupada erälde ja sü̈̈dävä pada erälde. Tuu om jo väega kuuh, jovva-i timmä nii ar mõskõ', hot' mõsõtki, tä iks pilgahhas. ${ }^{33}$

ERA II 286, 126/8 (93) < Se, Vastseliina v, Ljuta k - Ello Kirss < Ode Tammist, s 1868 (1940).

${ }^{29}$ 'Naisterahva loomus peab ka paastumisest palju kindlamini kinni kui mehel. Paastumine oleks ammu seto rahva seast kadunud, kui naised sellest nii lõdvalt ja nõrgalt kinni oleks pidanud kui mehed. Mehed, kes „maa pool” linasid käivad rabamas, kaltse korjamas jne, söövad kõik ka „suure paastu” ajal, mis ainult ette antakse, kuna naised lastega kodus selle üle väga valvavad, et paastupäeval midagi „söödava päeva” toitu suhu ei saaks.'

${ }^{30}$ ERA II 286, 159 (131) < Se, Meremäe v, Palo k - Ello Kirss < Ode Palo, s 1869 (1940).

${ }^{31}$ Caroline Walker Bynum, kes on analüüsinud keskaegsete naispühakute elulugudes esinevaid motiive, näitab, et paastumine (või maisest toidust loobumine) on sageli seotud teravdatud tähelepanuga teiste inimeste toitmisele (vt Bynum 1992: 141; ka Bynum 1987).

32 Tunnen religioosset seto naist (s 1933), kes on lapsest saati paastunud, kuna ta kodus peeti rangelt kinni paastuaegadest. Noore neiuna nägi ta hirmsa unenäo tapetud vasikast, misjärel loobus liha söömisest ka väljaspool paastuaegu. Tõenäoliselt mõjutasid seto laste toitumisharjumusi ka paastuaegsed traditsioonilised hirmutamised (preester lõikab keele välja, kui piima või liha sööd; jääd pimedaks, kui võid või mune sööd jms). Religioossete paastude ja taimetoitluse seoseid on hiljuti käsitlenud David Grumett ja Rachel Muers (2008; 2010; vt ka Wirzba 2011: 130 jj). Taimetoitlusest sajandivahetuse Venemaal on kirjutanud Darra Goldstein (1997) ja Ronald D. LeBlanc (1997).

33 'Paastumisega on niisamuti. Nüüd ei jõua täiskasvanud ära pidada, aga vanasti oli lastelegi selline seadus, et kaks aastat imetasid last, kolmanda aasta andsid kõiki sööke ja neljandal aastal panid paastuma. Ühe papi naine küll rääkis, et lastel on lubatud ka seitsme aastani süüa. [---] Mul endalgi on paastupada ja tavalise toidu pada eraldi. [Lihatoidu anum] on ju väga koos [lihaga], ei jõua seda nii ära pesta. Ükskõik, kui pesedki, ta ikka annab tunda.' 
Seto naiste jaoks võis paastumine olla väga selge ja konkreetne märk kontrolli saavutamisest oma maise keha üle. Nii nagu keskaegsete naispühakute (Bynum 1992: 140) või tänapäeva anorektikute (Puuronen 2001) jaoks, võis olla ka seto naiste jaoks paastumisest ja raskest tööst ära jäänud menstruatsioon selgeks märgiks sellest, et on saavutatud võit irratsionaalse keha üle (vt Kalkun 2008). Seto naised on uskunud, et menstruatsioonitsükkel on seatud naisele karistuseks (Kalkun 2007: 7), ning selline piinlike ja tülikate vaevuste võimalik ajutine ärajäämine on kindlasti paastujat tema katsumustes toetanud ja julgustanud.

\section{Rituaalsed toiduohvrid või toidu raiskamine?}

Lisaks paastudele oli muidki toitudega seotud religioosseid praktikaid, mis setodest kirjutajate tähelepanu pälvisid. Nii nagu oli ilmalikustunud ja protestantliku taustaga eestlastele arusaamatu paastumine, ei mõistetud ka setode kodumajandust ega üldisi toitumisharjumusi. Näiteks tundus võõrastele kummastav setode vaesuse juures nende külalislahkus ning majanduslik ebaratsionaalsus. Juba tsensor Jüri Truusmann mainib oma etnograafilises kirjelduses võrdlevalt, et „kui Baltikumi eestlased tunduvad isegi ihnsatena, on setud kaugel kokkuhoidlikkusest" (Truusmann 1890). Kui Soome etnoloog ja tollane Eesti Rahva Muuseumi juhataja Ilmari Manninen käis 1924. aastal setode juures välitöödel, kirjutas ta muuhulgas toidukultuuri silmas pidades, et setod on ,algelisel kultuurijärjel” ja lohakad ning suudavad mõelda ainult tänasele päevale (Manninen 1924: 40). Manninen kirjutab, et ta pole kuskil mujal näinud sellist toiduraiskamist kui suvel setode juures. Setomaad talvel (ilmselt paastuajal) külastades on Manninen aga šokeeritud valitsevast toidupuudusest ja näljast.

Suvel, kui Setumaal käisin, jäi minule mulje, et küllus valitses. Sellest vast ei maksa rääkida, et külalistele anti igal pool kõhutäis kõige paremat. Ka pererahvas ise raiskas halastamatult kõige kallimaid tooresaineid. Oli päris naljakas näha, kuidas võid söödi suure lusikaga. Tihti oli kohupiimamägi liua sees üleni kaetud kole paksu võikorraga. Või raiskamine oligi see, mis kõige rohkem silma torkas. Vahest praeti pekki ja muna koos. [---] Aga talvel? Siis saab Setumaal rändaja vahest nälga kannatada. [---] Puudus oli tõesti üllatav, imelik, arusaamata. Lehmad ei lüpsnud, kanad ei munend, liha oli otsas, kohupiim otsas, suvine või ammugi otsas, kala ei ole, suhkrut ei ole, teed ka mitte. Ei olnud tihti suurtes taludes külalistele midagi muud anda kui rukkileiba. Kontrast suvisega võrreldes oli äärmine (Manninen 1924: 41).

Lisaks teistsugustele igapäevastele söömisharjumustele ja kodumajanduse erinevale ülesehitusele kuulusid setode usupraktikate juurde ka mitmesugused eestlastele võõrad ja imestama panevad kombed. Setode toiduohvreid ikoonidele ja pühamutesse toidu viimist on setodest kirjutajad näinud kui kultuuri vanapärasele arenguetapile viitavat paganlikku relikti (Hagu 1999: 8788; Loorits 1951: 314; 1959: 5). XIX sajandi lõpus on mitmed autorid kirjeldanud, kuidas setod on eriliselt austanud Petseri kloostri Nikolai kirikus asuvat 
Možaiski Nikolai pühakuju (Bome 2006). Kevadisel nigulapäeval olevat lisaks tavalisele pühakuju puudutamisele, suudlemisele, selle ees põlvitamisele või kummardamisele kuju huuli määritud või, rasva, vere ja meega ning lisaks tavapärasele küünalde ja paberlillede ohverdamisele on toodud pühakujule küpsetisi, võid ja kohupiima sellisel hulgal, et kuju nende alt on vaevalt paistnud. Lisaks üldlevinud munaohvritele lihavõtete ja suvistepühade ajal (Loorits 1959: 25) „toideti” näiteks Pelsi, Sulbi ja Väiko-Rõsna külade tśasson'ates Püha Anna mälestuspäeval seda ikooni lambalihaga (Setumaa 1928: 90; Saarlo 1996: 116; Mägiste 1977: 168-170). Samamoodi nagu mõnedes külagruppides toodi Püha Anna ikoonidele lambapäid ja villa, toodi teistes külades külakabelisse Antoniuse auks seapea (Piho 2011: 39). Jüri Truusmann kirjutab, et setodel oli üldine komme tuua kirikutesse eri tähtpäevadel mitmesuguseid loomakasvatus- ja põllumajandussaadusi. Kolmainupühal toodud Pankjavitsa kirikusse mune, võid, kohupiima, peetripäeval juustu. Annid asetati ikoonide ette ja laskuti palvesse (Truusmann 1890: 39-40; Loorits 1959: 32). Treski ja Miikse küla Ristija Johannese tśasson'atesse viidi pühaku mälestuspäeval võid, sõira, kohupiima ning neid kutsuti seetõttu piimätśasson'ateks (Valk 2011: 85). Saatse kiriku Pühale Paraskeva ikoonile olevat viidud võid ning jäetud see hiljem kerjustele (Loorits 1959: 27).

Toiduohvrid ikoonidele või pühakodadele olid omakorda seotud toiduannetustega preestritele, kloostrile, vaestemajadele, leskedele ja santidele. Söögi annetamine vaestele on seto naiste jaoks olnud seotud surnute mälestamisega, kirikupühade ja pühapaikadega ning söögi annetamisel on olnud selge religioosne tähendus praktilise kõrval. Paljude kirjelduste ja mälestuste kohaselt kogunesid XX sajandi alguses Setomaal kirikupühade ajal kirikute ja surnuaedade lähedusse arvukad santide ja kerjuste hulgad, kellele seto talunaised ande tõid, kuna teadsid, et heategude eest tasutakse teises ilmas (Kallas 1898: 181; Manninen 1924: 17; Kirss 1998: 114). Mõnedes Setomaa piirkondades oli tavaks enne lihavõtteid teha toiduannetusi vaestemajadele, et patte andeks saada enne ainsat armulaual käimist aastas. Kui setode asualal asuv Petseri klooster läks 1930. aastal Eesti Apostlik-Õigeusu Kiriku sinodi alluvusse ning seda reformiti eestimeelsemaks, keelati tähelepanuväärselt muuhulgas munkadel seni kombeks olnud vaeste toitmine (Lõuna 1999: 64; 2003: 82). Petseri kloostri juures peatuvaid kerjuseid kujutati Eesti ajakirjanduses humoristlikult, näidates neid pillavate ja muretutena (nt Petseri 1937).

Lähedase surma korral pidasid setod oluliseks teha lesknaistele, vaestele ja santidele annetusi ning uskusid, et just nende eestpalveid kadunukeste eest võetakse kõige kiiremini kuulda. Kui keegi suri, viidi Petseri vaestemajja toidu- või riidekraami, muidu võis surnu end unes näidata näljas või paljana. ${ }^{34}$ Usuti, et 40 päeva jooksul tehtud annetused võiksid parandada lahkunu positsiooni teises ilmas ${ }^{35}$, ning populaarsed muistendid räägivad ihnsast rikkast, kellel pärast surma on hingelaual vaid kolm leivakoorukest või mudane leivapäts, kõik, mis elu jooksul vaestele antud ${ }^{36}$ (Loorits 1959: 43). Seto matusekombestiku väga oluline osa oli peieliste söötmine. Kui keegi talust suri, pidi

${ }^{34}$ ERA II 248, 665/6 (2) < Se, Petseri v, Uus-Butõrka k < Meremäe v, Miikse k - Olga Palsi $<$ isalt, 45 a (1939).

${ }^{35}$ ERA II 194, 424 (25, 26) < Se, Vilo k < Ungavitsa k - Ello Kirss < Ann Pääsläne, s 1863 (1938).

${ }^{36}$ S 57778 (7) < Se, Vilo v, Saptja k - Anna Tammeorg < Maria Taptal (1933); ERA II 194, 270/1 (3) Se, Vilo v, Radaja k < Parkanova k - Ello Kirss < Mat'ro Müürüorg, s 1868 (1938). 
tapma mõne kodulooma (lammas, vasikas, kukk) koolnu nime pääle. Ilm väist veristämäldäq ei võinud matuseid pidada, et karjaõnn jääks majja. ${ }^{37}$

Usk sellesse, et toidu annetamisel ja viletsate eest hoolitsemisel on otsene seos inimeste positsiooniga teises ilmas, on seto perekondades elanud veel XX sajandi keskelgi. Näiteks on kuulsa seto lauliku Anne Vabarna tütar Matrjona Suuvere 1976. aastal itkenud ema haual sellest, kuidas talle on unes näidatud, et ema Anne on taevasse võetud ning Jeesus ja Maria toidavad teda, kuna ta on maa peal elanud jumalakartlikku ja vooruslikku elu. Matrjona loetleb itkus ema heade tegudena üheksa lapse üleskasvatamist ning tähelepanuväärselt ka seda, et ema olevat ikka kerjustele ja santidele süüa andnud ning öömaja pakkunud.

Kuku maamakõnõ, õga sa santõ joht söömäldä lasõ-s,

kuku maamakõnõ, maŕa lasõ-s joht üvä maitsmald.

Kuku maamakõnõ, kui jäivä-ks na sandi’ iltsõsta,

kuku maamakõnõ, pääle päävä kui minegu jäivä’,

kuku maamakõnõ, sis jäivä-ks sinnä sandi’ üüsestä,

kuku maamakõnõ, mi majja nä magama jäivä' ${ }^{38}$

KKI EMH 2942 < Se, (Järvesuu v) Tonja k - S. Suhonen, H. Keem - Matrjona Suuvere, 77. a (7. IX 1969) (Pino, Sarv 1981: 27).

Ilmselt oli külalislahketel setodel meeles populaarsed legendid Jeesusest, kes külastab sandi või vanakese kujul rikast ja vaest perekonda. Kerjuste ja rändajate lahke kohtlemise nõuet on rõhutatud mitmetes setode hulgas populaarsetes legendides, näiteks „Jumalal külas” (AT 751A*), „Patune ema” (AT 804), „Kolm hingeaset” (AT 840B) jt (Salve 1993: 2609; vt ka Loorits 1959: 20).

\section{Religioossed tähtpäevad või joogiorgiad?}

Setomaal elab siiani tihedalt kirikukalendriga seotud külapühade traditsioon (Lõiv 2008). Igas külas või küladerühmas on oma pidupäev, mõnele kirikupühale või pühaku mälestuspäevale langev püha. Pidustusi on setod ise kutsunud sõnadega kirmask, kirmas või küläpraasnik. ${ }^{39}$ Enamasti on külapeod seotud lähedalasuvate kirikute või kabelite nimipühadega. Pidustused, kuhu kõik antud piirkonnast pärinevad inimesed üritavad ikka kokku tulla, algavad enamasti teenistusega kirikus või kabelis ja surnute mälestamisega kalmistul ning jätkuvad küla avalikus ruumis toimuva mitteformaalsema peoga, hiljem aga intiimsemate jätkupidudega peredes. Noored võisid külastada ka kaugemate külade kirmaskeid, kuid enamasti piirduti vaid lähiümbrusega. Mõnes piirkonnas on toimunud külapeoga seoses ka laat ning pidustused on olnud traditsiooniliselt kohaks, kus noored tutvusid ning vanemad tegid oma laste abieluplaane. Kirmaskitel lauldi ja tantsiti ning nendega käisid kaasas

\footnotetext{
${ }^{37}$ H II 69, 825/6 (1) (1903).

38 'Kallis mammakene, ega sa sante söömata ei lasknud, mari, sa ei lasknud tera maitsmata. Kallis mammakene, kui jäid sandid hilja peale, peale päeva minekut, kallis mammakene, siis jäid sandid ööseks, meie majja magama jäid.'

${ }^{39}$ Sõnad kirmask ja kirmas on setodel tõenäoliselt vene keelest laenatud (кирмаu), kuhu sõna omakorda on jõudnud saksa keele vahendusel (Kirchmesse).
} 
rituaalsed söömingud ja joomingud. Paastu ajal kirmaskeid ei peetud ning suur hulk külapühi jäi just suvisele ja sügisesele ajale.

Kui XIX sajandil loodud kirmaskite kirjeldused on küllaltki romantilised ja positiivse tooniga, siis pärast seto alade Eesti Vabariiki integreerimist XX sajandi algul muutub kirmaskite representatsioonide toon järsult. Kui XIX sajandil kirjutati hõberahade helinal tantsivatest ja laulvatest seto naistest ja neidudest, kes hõljusid kirmaskil nagu luigeparv valgetes pealisriietes (nt Veske 1877: 4), siis XX sajandi kirjeldustes hakkavad domineerima purjus inimesed ja pussitamised. Alkoholi ja eetri ${ }^{40}$ liigtarvitamine ning majanduslik kahju, mida vana kalendri järgi tähistatavad rohked kirikupühad näisid riigile tekitavat, sundisid 1930. aastail nii kohalikes kui üleriigilistes lehtedes avaldama kümneid negatiivseid lugusid setode joomapidudest ja nendega seotud kriminaalkroonikast. Kirmaskite kohta hakati ajakirjanduses järjekindlalt kasutama setode jaoks tundmatut venekeelset terminit guljänje (ka gulänje) vihjamaks nende pidude venepärasusele.

Pärast setode asuala liitmist Eesti Vabariigiga üritasid riigivõimud viia läbi mitmeid muutusi ka õigeusukogudustes. Radikaalseimad muudatustest olid seto-vene segakoguduste lahutamine (Lõuna 1999: 68-69; 2003: 111-112) ning kohustuslik uue kalendri kasutuselevõtmine. Gregooriuse kalendri kasutuselevõtmine põhjustas esialgu vastuseisu isegi ilmalikes institutsioonides, saati siis konservatiivses kirikus (Lõuna 1999: 59). 1924. aastal teatavad ajalehed, kuidas rahvas tuli Petseris vana kalendri järgi viiristmise pühaks kirikusse ning nõudis selle tähistamist. Kui preester seda ei teinud, hakanud rahvas ise epifaania teenistuse laule laulma ja lärmama, segades nii teenistust (Petserimaalt 1924). Rahva rahustamiseks olid uue kalendri järgi teenistusi pidavad preestrid sunnitud sageli riigivõimu esindajana politsei appi kutsuma. Samas oli ka suur hulk preestreid, eesotsas kloostriülem isa Joanniga, uue kalendri kirikus kasutamise vastu (Lõuna 1999: 59; Risch 1937: 128). Sageli peeti traditsioonilisi usuriitusi vana kalendri järgi, kuid nimetati neid mingite poolvalede või uute nimedega. Näiteks 1933. aastal korraldati Petseris vana kalendri järgi traditsiooniline iljapäivä ristikäik, kuid nimetati see koolerast ja katkust vabanemise mälestuspäevaks. Samamoodi vassiti ka Kuljes, kus vana kalendri järgset iljapäivä teenistust nimetati kiriku nurgakivi panemise mälestuspäevaks (Petserimaa 1933).

1930. aastate ajakirjanduslik diskussioon seto külapühade üle rõhutas setode ja venelaste eestlastest erinevat tööeetikat ja elulaadi. Õigeusklike rohked kirikupühad ja nende tähistamise eluliselt oluliseks pidamine tundus väga erinev eestlaste protestantlikust tööeetikast (vt ka Annist 2011: 100). Lisaks sellele, et rahvalikke laulu-, tantsu- ja söömapidusid kujutati kui venepäraseid, labaseid ja kuritegelikke, rõhutati ka pidutsemise amoraalsust ja suurt majanduslikku kahju, mida see põhjustab. Aktiivsemad vastased võtsid kokku arvutada, kui palju riik sellise pidutsemisega kaotab. Kirjeldustes muutusid järjest suuremaks kirmaskite arvud. Kui XX sajandi lõpu seto kultuuri kirjeldustes (Lõiv 2008: 247; Siruli 1999: 130-131) kirjutatakse tagasihoidlikult rohkem kui 50 kirmaskist, siis 1930. aastatel räägiti 245 ja

${ }^{40}$ Eetrit hakati Eestis mõnuainena tarvitama juba XIX sajandil. XX sajandi alguse karskustegelased väitsid, et komme on muudesse Eesti piirkondadesse jõudnud just setode käest (Kalling 2004: 115). Setodel on mitmeid traditsioonilisi uskumusi eetri mõjude kohta ning eetri tarvitamine on setode hulgas siiani tuntud. 
enamast külapeost (E. 1933; Petseri 1937; Lõuna 2003: 85). Samuti muutusid kirmaskite representatsioonides järjest suuremaks pidudest osavõtjate arvud. Kui Mihkel Veske luges 1875. aastal Miikse kirmaskil üles 80-100 naist (Veske 1877: 4), siis 1932. aastal väideti Värska kirmaskist osavõtjate arvuks 2000 (Ed. 1932) ning 1933. aastal räägitakse juba 10 000-18 000 osavõtjaga kirmaskitest (E. 1933; Petserimaa 1933). ${ }^{41}$ Näiteks üks hüperboolne ja numbritega manipuleeriv kirjeldus 1933 . aastast. $^{42}$

Petserimaal peetakse aasta jooksul 196 kindlapäevalist gulänjet, peale selle veel 53 gulänjet, mis seotud liikuvate pühadega, niisiis kokku 249 rahvapidu. Osa võtab neist 300-18000 inimest. Suuremate gulänjekohtade hulka kuulub Satserinna oma 10000-12000 osavõtjaga, Kulje 3-4000, Laura 7-8000, Petseri 3-4000, Irboska 4-5000, Tailova 8-10000 ja Pankjavitsa 10-18000 osavõtjaga. [---] Gulänjete jaotusest kuude järele näeme, et nad langevad oma enamikus kibedale tööajale. Kindlapäevalisi gulänjeid on jaanuaris 16 , aprillis 3 , mais 17 , juunis 7 , juulis 24 , augustis 37 , septembris 16 , oktoobris 9 , novembris 46 ja detsembris 21 . Veebruar ja märts jäävad paastumise jaoks. Kui siia juurde arvata veel ristikäigud ja gulänjed liikuvatel pühadel, näeme, milliseks nuhtluseks pidutsemine kõige paremal tööajal kujuneb. Selle juures ei tohi unustada, et gulänjeks kunagi ühest päevast ei jatku, vaid selle kestvus tuleks lugeda 2 päevast kuni 1 nädalani, hulka arvates ka „peaparandamise” ajad. [---] Arvestame keskmiselt iga gulänje kohta osavõtjaid ainult 300 inimest, kes oma täieliku tööpäeva kaotsi lasevad. 249 gulänje kohta läheks aasta jooksul kaduma sellega 74700 tööpäeva. Võtame tööpäeva hinnaks ümmarguselt poolteist krooni ning üksi töötasu kadu aasta jooksul teeks välja 11203000 senti. Harilikke nädalapühasid, ristikäikudele viidetud aega jne. ei julge siia juurde enam arvatagi (E. 1933).

1930. aastatel loodud kirjeldused tööpäevadel pidutsevatest setodest (nt Põldmäe 1938: 5) harmoneerusid juba varasema retoorikaga, mille kohaselt setod olid primitiivsed ja lohakad ühepäevainimesed. Iseloomulikult võrdlesid nii folkloristid kui ka ajakirjanikud venelasi ja setosid, kes olid kallil heinaajal pidutsenud, samal ajal kui virkadel eestlastel oli hein ammu tehtud (E. 1933; Põldmäe 1938: 5). Samuti kirjutavad lehed, kuidas eesti peremehed on hädas seto soost töölistega, kes kõige kallimal tööajal kiirustavad rahast ja ajast hoolimata oma koduküla kirmaskile pidutsema (Ringi 1933) või õpetavad eesti noortele venepäraseid peokombeid (Maa 1934).

Kuna seto külapühade juurde käisid ka rituaalsed söömised ja joomised kalmistul, külaplatsil ja kodus, siis said kirmaskite kirjelduste üheks osaks purjus inimesed (ka naised ja lapsed) ning mõrvadega lõppevad kaklused. ${ }^{43}$

${ }^{41}$ Tõenäoliselt on numbrite nii suured erinevused tingitud ka sellest, et XX sajandi lõpu setode uurijad on arvestanud rangemalt vaid seto külade kirmaskeid, kuid 1930. aastate ajakirjanduses loetakse ilmselt ka vene külade pühi.

${ }^{42}$ Ka XIX sajandi lõpu ja XX sajandi alguse Venemaa karskuse eest võitlejad väitsid, et õigeusklikud pühad võtavad enda alla „enam kui kolmandiku aastast” ning tähtsamaid religioosseid tähtpäevi võidakse pühitseda isegi kuni kolm päeva (Herlihy 1991: 134).

${ }^{43}$ 1930. aastail käsitlesid näiteks ajalehtede Petseri Uudised ja Võru Teataja kriminaalkroonikad meeleldi Setomaal toimunud pussitamisi ja taplusi. Sageli oli kirjutiste toon patroneeriv või parastav, näiteks käsitleti Petseri Uudistes ka nelja- ja kolmeaastase seto lapse mänguhoos saadud vigastusi „pussikultuuri” diskursuses (Pussikultuur 1933). 
Eestlaste loodud seto kirmaskite kirjeldustes rõhutati metsikut joomist ja lööminguid. Karskusliikumise aktivist Helmi Rosalie Mäelo 1930. aastail nähtud seto paabapraasniku kirjelduses domineerivad purjus naised, kes hoiavad ühe käega lapsi ja teisega kummutavad pudelist ning „laulavad ja kriiskavad” laste nutukisa saatel (vt Lõuna 2003: 163). Võõpsust pärit kirjandusteadlane Daniel Palgi võtab oma seto kirmaski kirjelduse kokku sõnadega „[g]ulänje tagatipuks olid seaksjoomised ja löömingud" (Palgi 1994: 14).

1880. aastatel lõpus alanud karskusliikumine ${ }^{44}$ oli XX sajandi alguseks Eestis kõvasti kanda kinnitanud ning sidunud end tihedalt marurahvuslike ja rassihügieeni ideedega ${ }^{45}$. 1924. aastal alustas Karskusliit koostööd Eesti Eugeenika Seltsiga Tõutervis (Eesti 1924) ning seltsi ajakirja veergudel arutati näiteks „alaväärtuslike” ja „kuritegelike” isikute steriliseerimise küsimust (Madisson 1925). Setode külapidusid ja sealset joomist käsitleti karskusväljaannetes kui rahvust nõrgestavat nähtust, mis tuli „madalast haridustasemest, halbadest sotsiaalsetest oludest ning vanadest kahjulikest tavadest" (Petseri 1925: 349). Leiti, et viinahimulisi setosid võiks päästa ainult täielik keeluseadus, kuna karskuspropaganda võiks mõjuda ainult noorematele inimestele. Kritiseeriti seto laulupidusid kui rahvahariduse seisukohast jõuetuid üritusi, kus lauljad viivad saadud honorari kohe kõrtsi (Lind 1925: 317). Setode joomisest kirjutajad kasutasid sageli juba traditsiooniks saanud „madalama arengutaseme" retoorikat.

Oma suguvendadest eestlastest on setud igapidi kaugele maha jäänud. Üksnes joomises on nad teistest suure sammu ette jõudnud. Joovad kõik: mehed ja naesed, noored ja vanad, ka lastele antakse „praasdniku” ajal oma... tops liikvat, kui mitte muidu, siis vägisi. Niisuguse koleda joomise järeldused paistavad setukeste seas iga sammu pääl teile silma: mitmesugused vaimu ja ihu haigused, vaesus ja varguse himu valitsevad siin piirita (Setukene 1907: 8, 9).

1930. aastatel sekkusid riigivõimud seto külapühade traditsiooni ning lisaks sellele, et kirmaskeid ei lubatud enam pidada vana kalendri järgi, hakati neid politseijõudude abil ka sootuks ära keelama. Sealjuures rõhutati sageli, et kirmaskite traditsioon on uus ja kirikupühadega ammu oma sideme kaotanud (Põldmäe 1938: 8; Rammul 1935: 49; E. 1933; Petseri 1933; Gulänjed 1933). Setode spontaansed ja ametlikuks kogunemiseks registreerimata peod ei sobinud Eesti Vabariigi seadustega ning tekitasid kaebusi (E. 1933). Kuna religioossete tähtpäevade tähistamist ei saanud otseselt keelata, keelati esmajoones ära ainus teadaolev mittereligioosne Kahkva küla ninnikirmask, mida peeti juuli teisel pühapäeval setode ja eestlaste asuala piiril (Ringi 1935). Peod siiski ei hääbunud, vaid vahetasid vaikselt oma asupaika, näiteks seesama Kahkva kirmask kolis mõne aja pärast „eesti poole pealt” setode asualale Puugnitsa külla (Pino 1986) ning kakluste pärast keelatud peetripäeval peetav Kitsõ küla kirmask kolis olulise tee ja kõrtsi lähedusest

${ }^{44}$ Eesti karskusliikumine sai algtõuke Soomest, nimelt sai seal karskusäratust rahvaluule uurija ja pastor M. J. Eisen, kes tutvustas karskuspropaganda ideid ka Eestis ning ühtlasi tõi kaasa ühe karskusseltsi põhikirja, mida kasutas eeskujuna esimene eesti karskusselts Toris (Jansen 1998: 599).

${ }_{45}$ Samasugused arengud toimusid ka Soome karskusliikumises, vt Mattila 1999; Apo 2001: 209-212. 
kõrvalisema asupaigaga Uusvada külla. Inimeste laialiajamiseks hakati järjekindlalt kasutama ratsapolitseid, kumminuiasid ja pipragaasi ning sellest vägivaldsest praktikast kirjutati lehtedes uhkusega (Petseri 1937). Seto külapühade teemat arutati kõige kõrgemal tasandil, näiteks 1932. aastal andis sise- ja kohtuminister A. Anderkopp aru oma tegevusest Petserimaal korra tagamiseks.

Muuseas oli kõne all ka korraküsimus piiriäärsetes maades, eriti Petserimaal, kus kuulsaks saanud n. n. „guljänjed”. Minister seletas, et raske on Petserimaal nii traditsiooniliseks kujunenud „guljänjeid” täiesti ära kaotada, sest need on ikkagi kohalikkude elanikkude kombed. Küll aga ollakse selle eest valvel, et „guljänjetel” korda ei rikuta. Viimati on, näiteks, ühe "guljänje" puhul tarvitatud hea eduga pipragaasi ja ka edaspidi tahetakse seda vahendit kasutada (Põrandaalustest 1932).

Mõned üksikud hääled püüdsid küll setode eest kõnelda ning kaitsta nende põliste külapühade traditsiooni. Näiteks kirjutas Friedebert Tuglas oma reisikirjas, et „gulänjeid” ei tuleks hävitada. „Rahva tase peab tõusma, siis gulänje kaotab oma varjuküljed. Nad ei tule kokku kaklemiseks vaid rõomusolemiseks" (Tuglas 1936). Samas kirjutas paar aastat enne Tuglast külapühade toetajatele sapise epigrammi „Gulänjed ja kumminui” luuletaja Henrik Visnapuu, kes naeruvääristas kirmaskitraditsiooni ja selle kaitsjaid ning rõhutas pidustuste vägivaldset poolt.

Küll kole on nüüd politsei: gulänjet teed, ta ütleb: ei ning tuleb kummi nuudiga, kui kakled oma pruudiga.

Kui tahad pussi proovida, häid pühi sõbral soovida, siis ikka jälle kumminui teeb sinust vaga turteltui.<smiles>C1[AlH][AlH]1</smiles>

Riik rõhub hirmsa auruga, gulänjel ei saa jaurata.

Ei lasta lõhki lüüa päid.

Oh! Läind gulänje päevi häid!

Mis on üks püha Setumaal, kui kakeldagi seal ei saa.

Riik liikvat laseb rüübata, kuid kaikaga'i saa hüübata, sest üle pee käib kumminui, ja ole vait kui turteltui.

(Visnapuu 1933: 2) 


\section{Kuidas mõista võõrast paastu ja pidu?}

Pärast seto alade Eesti Vabariiki integreerimist tõusid teravalt esile erinevustest tingitud kultuurikonfliktid. Moderniseerunud eestlased vaatasid setode kui oma „nooremate vendade” peale ning üritasid nende kultuuri ja elulaadi kui vanapärast ja tagurlikku reformida. Ootamatult tekitasid lisaks sotsiaalmajanduslikele ja hariduslikele erinevustele suuri konflikte ka religiooni ja kombestikuga seotud nähtused. Ilmalikustunud eestlaste ja religioossete setode arusaamad igapäevastest usupraktikatest ja vagadusest, aga ka tervishoiust ja kodumajandusest olid nii erinevad, et konfliktid olid kohati lepitamatud.

Eesti Vabariigi koosseisu kuuluvate setode religioosseid tavasid hakati vaatama uue pilguga, setode traditsioonilised paastud seoti tervishoiu diskursusega, toiduohvrid majandusega ning kirikupühad kuritegevuse ja alkoholismi diskursusega. Mõõdeti usupraktikate majanduslikku kasu või kahju ning mõju tervisele, arvestamata, et religioossete setode jaoks oli traditsiooniliste rituaalsete praktikate järgimine, nagu näiteks kirikupühade tähistamine ja lahkunute meelespidamine, neist kategooriatest väljaspool seisev ning ainuvõimalik käitumine.

Lähiümbruse külapeod, palverännakud kaugetessegi pühamutesse, erinevad kirikud, tśasson'ad, ikoonimajakesed, aga ka pühad puud ja kivid panid paika setode „püha geograafia”. Paastude ning pidusöökide ja joomingute vaheldumine struktureeris setode aasta ja pani paika vaimselt, füüsiliselt ja seksuaalselt aktiivsemad ja passiivsemad perioodid. Kui 1920. aastail üritati setosid moderniseerida ja ilmalikustada, hakkasid need seni kindlad struktuurid aegamisi lagunema. Usk ja selle väljenduseks olnud religioossed praktikad, mis olid olnud setode endaksolemise üheks aluskiviks, stigmatiseeriti „vene usuks” ja „ümberrahvustamise”, st venestamise tööriistaks. Setodest pidi kiiresti saama protestantlike eestlastega sarnane rahvas. Eesti ametlik poliitika rõhutaski, et Petserimaal elab vaid kolm rahvust: eestlased, venelased ja lätlased. Setod olid näiteks tolleaegse Eesti siseministri jaoks lihtsalt võõra mõju all venestunud eestlased, kes tuli tagasi võita.

Petseri eestlased tulevad kooli, kirjanduse ja seltskondliku läbikäimise kaudu viia lähemasse ühendusse Eesti kultuuriga, millest nad võõra mõju all elades aastasadasid lahutatud on olnud. Nende vaimuelu peab loomulikult ühte sulama Eesti rahva üldise vaimuilmaga (Hünerson 1928: 3).

Petserimaa elanikkond muutuski aegamisi järjest eestimeelsemaks ning seoses setode eestikeelse kooliharidusega hakkas setode eestistamise projekt järjest enam õnnestuma. Kui esialgu püüti suurema eduta külapidude traditsiooni nii politsei sekkumise ja trahvidega kui ka „tsiviliseeritud” alternatiividega katkestada (vt Rammul 1935: 49), siis mõnda aega hiljem hakkaski vanade religioossete traditsioonide järgimine harvemaks jääma. Petserimaa edumeelsem või siis eestistunum elanikkond tundis ühtäkki piinlikkust oma maa vabaõhumuuseumi kuvandi pärast (Manninen 1924) ning 1930. aastate lõpus hakati Petseri Žurnaali veergudel, aga ka üle-eestilises ajakirjanduses kirjutama Petserimaa edusammudest nii tervishoiuliste olude kaasajastamisel kui ka religioossete pühade vaigistamisel (nt Setumaa 1935). 
Elu ratsionaliseerub ka Petserimaal ja folkloristlik-etnograafilise kuldvasika küljest mureneb tükke. Seda on näha kõigil elualadel, kuidas oleva sajandi kultuurimõjud hakkavad läbistama isegi niisuguseid purunematuid müüre, nagu seda on näiteks usuelu poolt teataval määral tagurlikkusele sunnitud ning pidurdatud tervishoiu alalgi. Ristikäijate read jäävad harvemaks ja usuelu emfaatika raugeb normaalsemaisse raamidesse. Me märkame, et kultuur ja teadlikkus nivelleerivad siinsetki eluvoolu. Jääb see, mis on edasiviiv, jääb see, mis on kohane meile ning vastuvõetav (Vahi 1936: 4).

Setode toidu ja joogiga seotud traditsioonid, nii loobumised kui ka liialdamised, asetusid kindlasse religioossesse, sotsiaalsesse, poliitilisse ja majanduslikku konteksti. Religioossete praktikate eemilised ja eetilised tõlgendused olid aga spektraalselt erinevad ning sel murrangulisel ajal mingit mõistmist või kultuuridevahelist tõlget ei toimunud. XX sajandi alguses, kui seto kultuuri meedia- ja muud representatsioonid olid setosid võõristavate eestlaste käes, muutusid paastude ja pidusöökide kujutised groteskseks ning hakkasid rõhutama nende rituaalsete toimingute enesehävituslikku poolt. 1930. aastateks tõsteti need praktikad oma algsest kontekstist välja ja paigutati ühelt poolt arhailiste folkloorsete ja usundiliste nähtuste konteksti ning teisalt eelmodernse ja venepärase diskursusse.

Paastud ja pidustused kui võõrale ühed kõige kergemini märgatavad seto usuelu aspektid stigmatiseeriti nii seto kultuuri populaarsetes kui ka teaduslikes representatsioonides. Setode harrast ortodokssust ja traditsioonilisi pidusid tajuti noores Eesti Vabariigis kui rünnakut ühtse rahvuskehandi vastu, mis õonestas karske ja ilmaliku rahvusluse ideaale. Setod pidid eestistuma ning nende endi arvamust ei küsitud. Setode arusaamu oma usuelust jäädvustas vaid Eesti Rahvaluule Arhiiv kui kaduvat pärandit.

Artikkel on seotud Soome Akadeemia uurimisprojektiga „Embodied Religion. Changing Meanings of Body and Gender in Contemporary Forms of Religious Identity in Finland".

\section{Kirjandus}

A a b r a m s, Vahur, Kalk un, Andreas 2013. Hurda avitajaq Setomaal aastagil 1903 ja 1886 ja muid kommentaarõ. - Raasakõisi Setomaalt. Setomaa Jakob Hurda silmi läbi aastagil 1886 ja 1903. Värska: Seto Instituut, Eesti Kirjandusmuuseum, lk 198-215.

An n is t, Aet 2011. Otsides kogukonda sotsialismijärgses keskuskülas. Arenguantropoloogiline uurimus. Tallinn: TLÜ Kirjastus.

A p o, Satu 2001. Viinan voima. Näkökulmia suomalaisten kansanomaiseen alkoholiajatteluun ja -kulttuuriin. Helsinki: Suomalaisen Kirjallisuuden Seura.

B o m e, Helen 2006. Sacred Image as a Local Patron? The Icon of St. Nicholas of Mozhaisk in the Petseri monastery in Setu Folklore. - Folklore. Electronic Journal of Folklore, nr 34, lk 75-88.

B u c k, Villem 1909. Petseri eestlased. Tartu: Postimehe kirjastus.

B y n u m, Caroline Walker 1987. Holy Feast and Holy Fast. The Religious Significance of Food to Medieval Women. Berkeley: University of California Press. 
B y n u m, Caroline Walker 1992. Fragmentation and Redemption. Essays on Gender and the Human Body in Medieval Religion. New York: Zone Books.

E. 1933. 249 gulänjet aastas. Petserimaa kaotab oma meeletu pidutsemisega aastas umbes 100 milj. senti. $7000 \mathrm{kr}$. eest viina vaesema valla peol. - Postimees 19. IV, nr 90, lk 4 .

Ed. 1932. Pilte Värskast. Setude ja venelaste gulänje alevis. - Postimees 4. VIII, $\mathrm{nr} 180, \mathrm{lk} 4$.

Eesti 1924 = Eesti Eugeenika Seltsi „Tõutervise” töökava. - Tulev Eesti, nr 9, lk 279.

F o u c a u lt, Michel 2000. Mis on autor? - Vikerkaar, nr 11/12, lk 156-172.

Goldste in, Darra 1997. Is Hay Only for Horses? Highlights of Russian Vegetarianism at the Turn of the Century. - Food in Russian History and Culture. Toim Musya Glants, Joyce Toomre. Bloomington-Indianapolis: Indiana University Press, lk 103-123.

Gru m e t t, David, M u e r s, Rachel 2008. Eating and Believing. Interdistciplinary Perspectives on Vegetarianism and Theology. New York: T\&T Clark.

Grumett, David, Muers, Rachel 2010. Theology on the Menu. Asceticism, Meat and Christian Diet. London-New York: Routledge.

Gulänjed 1933 = Gulänjed uue kalendri järele. Kord paraneb. - Postimees 11. VIII, nr 186, lk 1.

H a g u, Paul 1999. Setukaiset - raja-aluen ortodoksivähemmistö. - Uskonto ja identiteetti. Suomalais-ugrilaisten kokemuksia ja vaiheita Venäjällä ja Neuvostoliitossa. Toim Teuvo Laitila, Tuija Saarinen. Helsinki: Suomalaisen Kirjallisuuden Seura, lk 82-95.

He retz, Leonid 1997. The Practice and Significance of Fasting in Russian Peasant Culture at the Turn of the Century. - Food in Russian History and Culture. Toim Musya Glants, Joyce Toomre. Bloomington-Indianapolis: Indiana University Press, lk 67-80.

H e r e t z, Leonid 2008. Russia on the Eve of Modernity. Popular Religion and Traditional Culture under the Last Tsars. Cambridge: Cambridge University Press.

H e r li h y, Patricia 1991. Joy of the Rus'. Rites and Rituals of Russian Drinking. - The Russian Review, kd 50, lk 131-147.

H u r t, Jakob 1904a. Über die pleskauer esten oder die sogenannten setukesen. - Anzeiger der Finnisch-Ugrischen Forschungen. Band III, Heft 3, lk 185-205.

H u r t, Jakob 1904b. Setukeste laulud. Pihkva-Eestlaste vanad rahvalaulud, ühes Räpinä ja Vastseliina lauludega. Ezimene köide. Helsinki: Soome Kirjanduse Selts.

H u r t, Jakob 1989. Mida rahvamälestustest pidada. Artiklite kogumik. Koost Ülo Tedre. Tallinn: Eesti Raamat.

H ü n e r s o n, Jaan 1928. Põllumeeste poliitika Petserimaal. - Petserimaa põllumeeste päev, 3. juunil 1928. a. Petseri, lk 3-6.

J a n s e n, Ea 1998. Seltsiliikumine - Eesti rahvakultuur. Toim Ants Viires, Elle Vunder. Tallinn: Eesti Entsüklopeediakirjastus, lk 591-614.

J ä ä t s, Indrek 1998. Setude etniline identiteet. Studia Ethnologica Tartuensia 1. Tartu: Tartu Ülikooli etnoloogia õppetool.

K a l k u n, Andreas 2004. 40 aastat Värska leelokoori Leiko. Värska.

Kalku n, Andreas 2007. Nähtamatu ja nähtav pärimus. Seto rahvaluule kogumisest ning menstruatsiooni ja sünnitusjärgse käitumisega seotud tabudest. Ariadne Lõng. Nais- ja meesuuringute ajakiri, nr 1/2, lk 3-18. 
$\mathrm{Ka} \mathrm{lk} \mathrm{u} \mathrm{n,} \mathrm{Andreas} \mathrm{2008.} \mathrm{A} \mathrm{woman's} \mathrm{voice} \mathrm{in} \mathrm{an} \mathrm{epic:} \mathrm{Tracing} \mathrm{gendered} \mathrm{motifs} \mathrm{in}$ Anne Vabarna's Peko. - Journal of Ethnology and Folkloristics, nr 2, lk 25-45.

$\mathrm{Ka}$ l k u n, Andreas 2011. Seto laul eesti folkloristika ajaloos. Lisandusi representatsiooniloole. Tartu: Tartu Ülikooli Kirjastus.

Ka lk u n, Andreas, Oj a m a a, Triinu 2009. Orthodox chanting and traditional singing: Conflicts and compromises. - Traditional Musical Cultures in Central-Eastern Europe. Ecclesiastical and Folk Transmission. Toim Piotr Dahlig. Warsaw: University of Warsaw, Polish Academy of Sciences, lk 157-180.

K a ll a s, Oskar 1898. Üht ja teist Setudest. - Eesti Üliõpilaste Seltsi Album. Teine leht. Tartu: Eesti Üliõpilaste Selts, lk 174-188.

Ka lling, Ken 2004. Liikva laened... õonistavad meie randa... - Eesti Rahva Muuseumi Aastaraamat XLVIII. Tartu: Eesti Rahva Muuseum, lk 109-134.

Kalling, Ken 2007. The Self-Perception of a Small Nation. The Reception of Eugenics in Interwar Estonia. - Blood and Homeland. Eugenics and Racial Nationalism in Central and Southeast Europe 1900-1940. Toim Marius Turda, Paul J. Weindling. Budapest-New York: Central European University Press, lk 253-262.

Ki r s s, Ello 1998. Setumaa 1938. - Mäetagused, nr 8, lk 108-130.

Kr e u t z w a ld, Friedrich Reinhold 1953 [1848]. Teateid rahvalauludest Pihkva kubermangus asuvate eestlaste juures. - F. R. Kreutzwald, Teosed. Maailm ja mõnda. Toim K. Taev jt. Tallinn: Eesti Riiklik Kirjastus, lk 105-112.

K u u t m a, Kristin 2005. Pärimuskultuurist kultuurisümboliks. Saami etnograafia ja seto eepose saamislugu. ELKA töid kirjandusest ja kultuuriloost 3. Tartu: Eesti Kirjandusmuuseum.

K ä r n e r, Ülle 2003. Püha Maarja legendid. - Tartu Ülikooli Lõuna-Eesti keele- ja kultuuriuuringute keskuse aastaraamat III. Tartu, lk 41-62.

L a u r, T. 1928. Keisrinna Katariina II. aegne eesti- ja venekeelne pihtimisekorra kava käsikirjas greeka-õigeusulise rahva jaoks Eestis. - Usuteadusline Ajakiri, nr 3, lk 143-151, nr 4, lk 225-242.

L e B l a n c, Ronald D. 1997. Tolstoy's Way of No Flesh: Abstinence, Vegetarianism, and Christian Physiology. - Food in Russian History and Culture. Toim Musya Glants, Joyce Toomre. Bloomington-Indianapolis: Indiana University Press, lk 81-102.

L e w i n, Moshe 1990. Popular Religion in Twentieth-Century Russia. - The World of the Russian Peasant. Post-Emancipation Culture and Society. Toim Ben Eklof, Stephen Frank. Boston: Unwin Hyman, lk 155-168.

L in d, G. 1925. Alkoholi uputus Petseris. - Tulev Eesti. Eesti Karskusliidu, Haridusliidu ja Eesti Eugeenika Seltsi „Tõutervishoid” häälekandja, nr 10, lk 317.

L o o rits, Oskar 1951. Grundzüge des estnischen Volksglaubens II. Häft 1, Häft 2. Skrifter utgivna av kungl. Gustav Adolfs Akademien. Uppsala-Köpenhamn-Lund: Carl Bloms Boktryckeri.

L o orits, Oskar 1959. About the religious concretism of the Setukesians. Suomalais-ugrilaisen Seuran Aikakauskirja, 61:5. Helsinki: Suomalais-ugrilaisen Seura, lk 1-49.

L õ i v, Merlin 2008. Kirmased Setumaal. - Setumaa kogumik. Uurimusi Setumaa loodusest, ajaloost ja rahvakultuurist. Toim Mare Aun, Merlin Lõiv. Tallinn: Tallinna Ülikooli Ajaloo Instituut, lk 246-268.

L õ u n a, Kalle 1999. Usuküsimus Petserimaal 1920.-30. aastatel ja kloostrisõda. - Ajalooline Ajakiri, nr 3/4 (106/107), lk 57-69. 
Lõ un a, Kalle 2003. Petserimaa. Petserimaa integreerimine Eesti Vabariiki 1920-1940. Tallinn: Eesti Entsüklopeediakirjastus.

Maa 1934 = Maa jutustab. Vene soost karjased eesti lastele guljänje-kunsti õpetamas. - Postimees 17. VI, nr 162, lk 8.

M a dis s o n, H. 1925. Allväärtuslikkude ja kurikalduvustega isikute sigivõimetuks tegemisest. - Tulev Eesti. Eesti Karskusliidu, Haridusliidu ja Eesti Eugeenika Seltsi „Tõutervise” häälekandja, nr 7/8, lk 201-211, nr 9, lk 261-266, nr 10, lk 291-297.

M a n n i n e n, Ilmari 1924. Setumaa muljeid. „Odamehele” kirjutanud E. R. Muus. - Odamees, nr 2, lk 39-42.

Mattila, Markku 1999. Kansamme parhaksi. Rotuhygienia Suomessa vuoden 1935 sterilointilakiin asti. Helsinki: Suomen Historiallinen Seura.

M ä g i s t e, Julius 1977. Setukaistekstejä. Suomalais-Ugrilaisen Seuran toimituksia 159. Helsinki: Suomalais-ugrilaisen Seura.

P a a s, Friedrich Eugen 1928. Sega-abielud ja nende mõju rahvusesse piiriäärsetes maakondades Eestis. - Eesti Kirjandus, nr 6, lk 294-306.

P a l g i, Daniel 1994. Murduvas maailmas. Mälestusi. Tallinn: Perioodika.

Petseri 1925 = Petseri Eesti Hariduspäev. - Tulev Eesti, nr 11, lk 348-349.

Petseri 1933 = Petseri tujukas august. - Postimees 25. VIII, nr 198, lk 4.

Petseri 1937 = Petseri ja tema guljänjed. - Postimees 26. III, nr 84, lk 4.

Petserimaa 1933 = Petserimaa gulänjed ettekäände all. Otsiti Ilja-päeva pühitsemiseks põhjusi. - Postimees 4. VIII, nr 180, lk 1.

Petserimaalt 1924 = Petserimaalt. Kalendri segadused Setumaal. Venelased ei taha uue kalendri järgi pühi pidada. Lärm Petseri kirikus. Preestrid politseid kaitseks palunud. - Päevaleht 26. I, nr 24, lk 6.

P i h o, Mare 2011. Setode usk ja Setomaa tsässonad. - Setomaa tsässonad. Toim Ahto Raudoja, Tapio Mäkeläinen. Tartu: SA Setu Kultuuri Fond, lk 13-60.

P i n o, Veera 1986. Kui kirmaskil ma käisin... - Töörahva Elu 26. VIII, nr 100, lk 3 .

P i n o, Veera, S a r v, Vaike 1981. Setu surnuitkud 1. (Ars Musicae Popularis [2].) Tallinn: ENSV TA Keele ja Kirjanduse Instituut.

P l a t h, Ulrike 2001. Grenzspiegelungen: Die Bedeutung der „anderen” Esten für die Konstruktion estnischer Identität (mitte des 19. Jahrhunderts). - Kollektivität und Individualität. Der Mensch im östlichen Europa. Festschrift für Prof. Dr. Norbert Angermann zum 65. Geburtstag. Toim Karsten Brüggemann, Thomas M. Bohn, Konrad Maier. Hamburg: Verlag Dr. Kovac, lk 252-270.

Pussikultuur 1933 = Pussikultuuri haritipp: Nelja-aastane poiss lõi kolme-aastasele vennale kääridega kõhtu. - Petseri Uudised 21. X, nr 42, lk 3.

Pu u ronen, Anne 2001. „Oikein” syöminen. Huomioita anoreksian terveyskulttuurisesta rakentumisesta. - Elore, $\mathrm{nr} 2$. http://www.elore.fi/arkisto/2_01/ puu201 (29. VI 2012).

P õ l d m ä e, Rudolf 1938. Rahvakultuurist, eriti rahva lõbutsemisvormidest Setumaal. - Eesti Noorus, nr 4/5, lk 3-10.

Põrandaalustest 1932 = Põrandaalustest, salapiiritusest ja seadustikkudest. Pisargaasiga „guljanjete” vastu. Jutuajamine sisekohtuministriga. - Postimees 8. IX, nr 210, lk 3.

R a m m u l, Aleksander 1935. Petserimaa tervishoiuline kirjeldus. Description sanitaire de l'arrondissement de Petseri. Beschreibung der sanitären Verhältnisse des Petseri-Kreises. Tartu: E. V. Tervishoiuvalitsuse ja Tartu Ülikooli Tervishoiu Instituudi väljaanne. 
R e i e r, Viktor 1922. Mälestused Setumaalt. - Eesti Kirjandus, nr 6, lk 173-176.

R i b e n i s, Karin 1993. Jakob Hurda võõrkeelsed etnoloogilised artiklid. 2. osa. Keel ja Kirjandus, nr 11, lk 665-672.

Ringi 1933 = Ringi ümber kodumaa. Võrumaalt. - Postimees 13. VIII, nr 188, lk 6. Ringi 1935 = Ringi ümber kodumaa. Petserimaalt. - Postimees 16. VII, nr 190, lk 5.

R i s ch, Helmut 1937. Die estnische apostolisch-rechtgläubige Kirche. - Kyrios. Vierteljahresschrift für Kirchen- und Geistesgeschichte Osteuropas, 2. Jahrgang, Heft 2, lk 113-142.

Rit c h i e, Susan 1993. Ventriloquist Folklore. Who Speaks for Representation? Western Folklore, kd 52, nr 2/4, lk 365-378.

S a a r l o, Liina 1996. Pühakutest ja mõnest muust ning mis nende ümber. - Palve, vanapatt ja pihlakas. Setomaa 1994. a. kogumisretke tulemusi. Vanavaravedaja 4. Toim Heiki Valk, Ergo Västrik. Tartu, lk 93-132.

S a lve, Kristi 1993. Toone tare. Tähelepanekuid setu surnuitkude žanridevahelistest ja geograafilistest seostest. - Akadeemia, nr 12, lk 2605-2621.

S a r v, Vaike 2000. Setu itkukultuur. (Ars Musicae Popularis 14.) Tartu-Tampere: Eesti Kirjandusmuuseum, Tampereen yliopiston kansanperinteen laitos.

S a r v, Öie, S a r v, Ain (toim) 2003. VI Seto Kongress. 9. oktoobril 2002. a. Verskah. Verska: Seto Kongressi Vanõbidõ Kogo.

Setukene 1907. Kiri Setumaalt. - Eesti karskusseltside aastaraamat. Üheksas aastakäik. Tartu: Eesti karskusseltside kesktoimekond.

Setumaa 1928 = August Ferdinand Tammekann, Edgar Kant, Johannes Voldemar Veski (toim). Eesti III. Setumaa: maadeteaduslik, tulunduslik ja ajalooline kirjeldus. Tartu: Eesti Kirjanduse Selts.

Setumaa 1935 = Setumaa eestistub kiiresti. Setu noorsugu kõneleb kõikjal eesti keelt. Ka venelased õpivad eesti keelt. Kalendriküsimus rahva seas on kaotanud oma teravuse. Setumaa kultuuristamine on andnud loodetud tulemusi. Postimees 2. VIII, nr 207, lk 4.

S i r u li, Sirje (toim) 1999. Seto kodu lugu. Tõravere.

Tru usmann, Jüri 1890 = Юрий Труусман, Полуверцы Псково-Печерского края. I. k, lk 31-62.

T u g l a s, Friedebert [F. T.] 1936. Munkade juurest Petserimaa külasse. - Postimees 14. VI, nr 158, lk 4.

U s s t a v, Karl 1908. Pihkwa eestlased. Tartu: Postimehe kirjastus.

V a h i, P. 1936. Rahva eduteedele eluõigust! - Petseri Žurnaal, detsember, lk 3-5.

V a lk, Heiki 2005. Lõuna-Eesti kaugemast minevikust. - Vikerkaar, nr 7/8, lk 124-129.

V a l k, Heiki 2011. Setomaa tsässonad. Pärimus, rahvausk ja kombed. - Setomaa tsässonad. Toim Ahto Raudoja, Tapio Mäkeläinen. Tartu: SA Setu Kultuuri Fond, lk 61-107.

V e s k e, Mihkel 1877. Bericht über die Ergebnisse einer Reise durch das Estenland im Sommer 1875 von Dr. M. Veske. Separatabdruck aus den Verhandlungen der Gelehrten estnischen Gesellschaft. 8. Band. 4. Heft. Dorpat: Laakmanns Buchdruckerei.

W i r z b a, Norman 2011. Food and Faith. A Theology of Eating. Cambridge: Cambridge University Press.

V i s n a p u u, Henrik [Tulihänd] 1933. Gulänjed ja kumminui. - Postimees 22. VII, nr 169, lk 2 . 


\section{Religious fasts and feasts in the representations of Seto culture}

Keywords: Seto people, religious fasts, village holidays, representations of Seto culture

The integration of the (orthodox) Setos into the Republic of Estonia established in 1918 soon revealed some conflicts due to cultural differences. The modernized Estonians tended to patronize their „lesser brothers” and to reform their culture and lifestyle, which was considered old-fashioned and reactionary. There was a change in attitude towards Seto religious practices in Estonia, namely, their traditional fasts became a public health issue, their food offerings were discussed in relation to economy and their celebration of church holidays all of a sudden belonged to the discourse of crime and alcoholism. The economic benefits or harms of Seto religious practices as well as their health effects were contemplated without considering the fact that for Setos the observation of traditional ritual practices, such as, for example, church festivals and commemoration of the departed was the only possible way and as such it did not partake of the categories of health or economy.

Based on the material kept in the Estonian Folklore Archives the article discusses the role of Seto religious feasts and fasts in their self-image as well as in their early representations, especially in the texts of the discourse of Seto Estonization, which began in the 1920s. It is demonstrated how the modernized Estonians, who emphasized secularism, abstinence and Estonian nationalism, used to stigmatize the fasts and religious feasts of the Seto, which were the most conspicuous features of their religious and everyday ways.

Andreas Kalkun (b. 1977), PhD, researcher, Estonian Literary Museum, Estonian Folklore Archives, andreas@folklore.ee 